\title{
Archiving the 1950 s
}

\author{
BRYONY DIXON
}

\begin{abstract}
A number of factors have contributed to the relative neglect of the I950s as a decade in British cinema history. It was a complex and unhappy decade in England and its films appear to have little contiguity or popular profile. The conventional back-of-a-postage-stamp view of British cinema history takes a strange skip and a jump when it comes to the r950s. Much is made of the so-called 'golden age' of British cinema in the I940s, but we tend go straight on to the ig6os and its 'New Wave' films. There is a vague sense of cosiness about the i950s commercial films which were produced by the Rank machine or lacklustre government-sponsored ventures. A sense of mounting irrelevance resulted in the Angry Young Men/Free Cinema backlash, which is often strangely attributed to the ig6os despite clearly having originated in the mid-I950s.

A major reason for this neglect of the I950s is that there has been no authoritative, dedicated history of the period of the Rachael Low type. Her History of British Film (1948-71) went up to the end of the I930s and no one has since attempted to cover the later decades in the same fashion. As a period of cinema history the i950s suffers from the auteur and genre models of examining film, neither of which methods really brings out the best in it. Another contributory factor to the lack of 'visibility' of its films is the fact that so few prints are available for researchers or filmgoers. If film programmers or lecturers want to show more than the classics from these years, they are hard pressed to find enough prints in screenable condition. As an archivist at the British Film Institute, I'll try to explain what survives and why, and some of the really awkward technical, preservation and access problems.

I must start with the nature of the collections relating to this period of film history, how they came to be where they are, and what was going on at that time in the international archiving world. The r950s is a particularly
\end{abstract}

Bryony Dixon is the Archival Bookings Officer for the British Film Institute in London. Here she writes about the physical existence of film of the 1950 s and the complex relationship between preservation and access. 
fascinating decade for the film archivist. Technically speaking there was a lot going on: the end of the nitrate era, the development of wide-screen and novelty formats, the increasing use of colour, advances in sound recording technology, lighter more portable $16 \mathrm{~mm}$ camera equipment, the coming of television. I am concentrating on the holdings of the British Film Institute's National Film and TV Archive (hereafter NFTVA). Appropriately for this story the name 'National Film Archive' not 'National Film Library' came into existence in 1955, with the word 'Television' added in I993. It is the largest collection of 1950 s films in the UK, but I am also going to refer to other large collections and to some related, non-film archives. I'm going to make some general comments on the relationship between academia and the archives which I think will be relevant to readers of this book.

Films physically survive for a variety of reasons, mainly economic, but sometimes technical. Film is, as Penelope Houston put it in her examination of British film archives, 'fragile, expensive and dangerous'. (See her excellent guide Keepers of the Frame published by the British Film Institute in I997.) Film companies may not want to store films once they have finished their run of commercial exploitation. Technological change contributed to a higher survival rate for films of the I950s than those of the silent era, 70-80 per cent of which have been lost. The move from nitrate to acetate 'safety' film stock was a big factor in improving the longevity of films, but it was the development of the film archives themselves which has done most to save our film heritage.

To assess the survival rate of the films of the 1950s means a complex calculation due to the way in which films have been categorised in the BFI's records, as fiction or non-fiction rather than as features, shorts, documentary television, newsreel and so on. This makes it impossible to run off a list from a database of 195 os British titles, but the following figures indicate that the majority of productions are extant. In addition very considerable holdings are still held in the major film libraries in this country for post-I95 $\mathrm{I}-2$ titles. The number of feature films produced for the period I950-9 according to figures given in the BFI Handbook (figures compiled by Screen Digest, Screen Finance and the BFI) is as follows:

Year Number of feature films

$\begin{array}{ll}\text { I950 } & \text { I25 } \\ \text { I95I } & \text { II } 4 \\ \text { I952 } & \text { II } \\ \text { I953 } & \text { I38 } \\ \text { I954 } & \text { I5O }\end{array}$




$\begin{array}{ll}1955 & \text { IIO } \\ \text { I956 } & \text { IO8 } \\ \text { I957 } & \text { I38 } \\ \text { I958 } & \text { I2I } \\ \text { I959 } & \text { I22 }\end{array}$

The total for the decade is $\mathrm{I}, 243$. For the same years the 1985 edition of Gifford's British Film Catalogue (published by David and Charles) gives a total of between 964 and approximately r,ooo films, depending on your definition of a 'feature film'. (His figure of 964 is for any fiction production over 60 minutes.) Discrepancies may also occur, of course, depending on what is meant by 'British', although in this period the definition was at least reasonably clear.

The NFTVA holds 5,493 titles for the years $1950-9$. Of these, I,I84 are listed as fiction titles (i.e. features, shorts, serials, television dramas, animation, trailers, etc.) and 37I are listed as being government-sponsored films. These figures have to be viewed with a certain amount of caution because, as with any archive, cataloguing tends to lag behind acquisition and there is probably a number of titles which have not been categorised on the computer record. The figures suggest that the bulk of the film industry's output is covered in terms of preservation. Recent acquisitions of British 'B' pictures, too, have filled some gaps in the collection and may not appear in these figures as yet.

Of course, for the film critic, historian or scholar the key issue is accessibility. Of the total number of titles held in the archive $\mathrm{I}, \mathrm{I} 84$ have viewing copies, meaning that the archive has several copies so one or more can be made available for viewing or screening. As a percentage of 5,493 , this is 22 per cent. At first sight this looks an astonishingly low proportion, especially when compared with the silent period for which we have viewing copies of about 80 per cent of the available films, or the I990s for which we have an excellent 97 per cent.

But this is not the full story. There are other film collections in the UK, but very few of these are equipped to run full preservation programmes and commercial companies are not obliged to provide access to their prints outside their business activities. I will come back to the availability of materials on other collections, but for the moment let's look at the technological reasons for the survival of film elements. 


\section{Nitrate}

There are good historical and technical reasons why the i950s scores so low on the accessibility scale. All archives tend to concentrate on their nitrate holdings, which broadly speaking covers the pre-cinema years up to I95 I-2 when the switch to safety stock was made. Nitrate film stock not only decays, but is also highly flammable. The NFTVA is one of very few locations in the UK allowed by law to keep nitrate. Not only does this mean that the archive has acquired huge amounts of nitrate film from the studios no longer able to store it, but also, due to nitrate's in-built decay mechanisms, the archive has had to duplicate it on to safety stock in order to preserve images for as long as possible. (Of course, a kind of archivists' Sod's Law has dictated that we now discover that 'safety' acetate stocks also decay from the so-called 'vinegar syndrome'.) The result of necessary concentration on nitrate copying is that the earlier material is being duplicated first as a priority. Time and resources will always limit the amount of copying done by the archive resulting from an access request rather than a preservation imperative. As it happens, a slight change of emphasis has occurred recently as archives have come to realise that predictions made about the longevity of nitrate may have been exaggerated. Partly, no doubt, the dangers were exaggerated in the past, in order to persuade government departments to fund preservation (the government only funded the programme after an accident at a chemical plant brought to the fore the dangerous substances legislation: it was never very concerned with arguments about preserving film as such) but it also led to the archive being a slave to the nitrate copying programme for many years. Recent rethinking has led to a shift towards a more access-led policy.

\section{Colour}

Other technical issues impact on the accessibility of I950s film material. By the early i950s colour was being used increasingly to differentiate film and television, and colour in particular had an enormous effect on the problems and costs of preserving and restoring film. The NFTVA has specialised in the past years on restoring Technicolor, including some classics of the i950s: Gone to Earth (1950), The Importance of Being Earnest (1952), Oh, Rosalinda! (1955), The Tales of Hoffman (1953). The BFI is currently attempting restoration of the I95 I production The Magic Box. A full-scale restoration of titles such as these can cost tens of thousands of pounds and really does require special funding or sponsorship. However, you can get magnificent 
results with Technicolor, which also has the advantage that it is possible to preserve the three separate film elements on black and white film stock thereby avoiding the fading problems of later colour systems. This is because 3-strip Technicolor is shot, as the name implies, on three separate rolls of film stock, each through a different-coloured filter. Restoration problems can arise if the film has shrunk at different rates so that the three images are difficult to register. In I950, the development of Eastman color negative film stock was to have a major impact on the production of colour film, making the 3-strip Technicolor camera unnecessary as a monopack negative containing all three primary colours made this step obsolete. After the midI95os nearly all colour film was shot on this stock and printed using one of a variety of processes including Technicolor, Deluxe, Warnercolor and Metrocolor. Improvements to colour grading came at the end of the decade.

\section{Formats}

The proliferation of formats in the 1950s engendered by the new competition from television brought with it its own set of restoration and preservation problems. Wide-screen and large formats, anamorphic systems and non-standard geometry such as VistaVision need specialised equipment to print and also to screen which means there can only be limited access to these films in performance. Specialised projection facilities and trained projection staff in Britain's remaining art-house cinemas become rarer year by year. Commercial cinemas are not geared to cope with alternative formats. This can limit access to film on film and we are likely to see much of this type of material only available on video and DVD in the future. (The exception to this may be the few remaining cinémathèques such as the National Film Theatre in London and a few of the larger regional film theatres.) The projection of film is likely to become a museum activity as the digital age replaces celluloid with electronic means of delivery to cinemas. At the same time it is also possible that transferring film into the digital domain may assist us, once the complex restoration and transfer process has been done, in delivering unusual formats with greater ease. (One successful gimmick of the 195 os was the development of 3 -D for the commercial cinema. Requiring specialised equipment to project and polarised or colour-filtered glasses to be worn by the public, this was enormously popular as an occasional spectacle - and still is. In this country a few stereoscopic films were made as exhibits for the Festival of Britain in $195 \mathrm{I}$, an occasion when interestingly much of the government-financed film culture infrastructure came in by the back door.) 'Gimmicky' formats still have the power to attract audiences. 
Wide-screen format, of course, is now the norm, but it is worth remembering that there is a whole generation of movie-literate youngsters who have never had a chance to see a $3-\mathrm{D}$ film at the cinema. New formats which were launched in the i950s such as CinemaScope, Cinerama, Techniscope, VistaVision and Todd A-O were developed specifically to be bigger and better than television, but smaller formats were also developed in response to a huge growth in amateur film-making and non-theatrical distribution and, of course, telerecording of TV on $\mathrm{I} 6 \mathrm{~mm}$ film. Eight $\mathrm{mm}$ took over from $9.5 \mathrm{~mm}$ as the amateur small gauge of choice for home movies. One small but noteworthy experiment funded by the BFI was Glenn H. Alvey Junior's 'Dynamic Frame' film process, used in the short film Door in the Wall (1956), which used masking in the printing stage to heighten dramatic effects. One example shows a character coming out of an alleyway with the picture masked to a thin vertical strip, and as the character emerges the picture widens out to its full horizontal width. But this was only an experiment, never to be repeated.

\section{Sound}

Magnetic sound recording began to be used in the film industry by the beginning of the I950s with improved methods of synchronisation, issued in I959. This had an enormous effect on documentary film-making styles which were already emerging (like Free Cinema). Wide-screen formats using any available film area for more picture availed themselves of the possibilities offered by magnetic tracks and several processes had sound on up to six tracks striped on to the show-prints. Again, in terms of presenting these films today, this poses a projection problem to all but the best-equipped cinemas.

\section{Travelling mattes and the jump cut}

These were further developed from I940s blue-screen processes, but using the new Eastman color negative stock and blue light. Some print-through of the original image seemed to be inevitable, as can be seen in productions such as The Ladykillers (1955). It is generally agreed that in the r950s directors could not resist the jump cut. Various productions in the decade used the jump cut and shock edits as a stylistic device (as in The Elusive Pimpernel (1950), Somebody Up There Likes Me (1956), Woman in a Dressing Gown (1957)). Barry Salt notes that such devices were much criticised by French critics until Truffaut adopted some of them himself. 


\section{A case in point: Women of Twilight}

Women of Twilight (1952) is a relatively little-known film of considerable social/historical interest, famous today for being one of the earliest films to get an ' $X$ ' certificate. This is, of course, the kind of film for which the British Film Institute should have materials in its collections. There is indeed a I $6 \mathrm{~mm}$ print available for research or screenings and a back-up $16 \mathrm{~mm}$ master, but we would hope to have good, original-format, $35 \mathrm{~mm}$ preservation and viewing material. In fact, the Romulus collection, now administered by Carlton plc, does have an available $35 \mathrm{~mm}$ print. In this case the private sector and the public archives have it covered, but it is still important that the national archive has preservation material in the long term. In these days of frequent mergers and de-mergers a sympathetic company attitude to archiving cannot be assumed.

As it happens Women of Twilight is not in particularly good shape, but the cost of restoring would be very high. If the BFI were to borrow original negative elements for duplication it would have to make inter-positive material, then duplicate sound and picture negatives (which would be the preservation master copies) and prints. This would cost at minimum (and this is just black and white!) $£_{\mathrm{I}} 6,000$. This is without 'restoration' work, i.e. repairs, grading, examination, testing, research, etc. The hopes of recouping any of this cost in film-hire charges is minimal as charges are $£_{50}$ at most and likely frequency of booking is a couple of screenings a year. At these prices it becomes more understandable why certain films are only ever seen on television or video. The art-works of film and television history, the basic data for critics and scholars, can indeed be elusive. Let us go back to the search for these phantoms.

There has always been a close if sometimes prickly relationship between academics and archivists. Film historians with limited time and resources for research can dislike the laborious and expensive processes of getting access to materials. Archivists can dislike the tetchy demands of students and researchers as they struggle against the clock just to rescue the films from decomposing for ever - and having to persuade successive uninterested government departments and funders to keep the money coming in. Despite the proliferation of courses in film studies and media studies, the funding of access to the source materials has not increased at all.

There can be surprisingly simple misunderstandings about what a film archive is. People who understand perfectly that they can't walk in and browse around manuscript collections of the British Library are illogically outraged when a film archive refuses them access to original masters, the film archival equivalent of the Gutenberg Bible. 
I'll make, from the archivist's angle, a comparison.

Our National Film and TV Archive can be seen as a hospital for sick film. Films come to us in all sorts of conditions, battered and bruised and with their in-built decay processes eroding them steadily from within. Sometimes they have only a scratch or two and can be left for the moment. We deal with the emergencies first, and the others when we can. Most of an archivist's job will be a race against time to deal with the emergencies, 'A and E', if you like. Other cases are diagnosed for treatment in the longer term and are sent up to the various 'wards'. Access policy is a way of prioritising the nonurgent cases for 'preservation' (keeping them alive as long as possible) and 'restoration' (patching them up and sending out into the world). Hospitals are complex, totally essential, and sometimes exasperating. So with the film archival hospital: thank goodness it is not a hospice. 